\title{
Corrigendum
}

\section{Validation of energy requirement equations for estimation of breast milk consumption in infants - Corrigendum}

\author{
Stefanie Schoen, Wolfgang Sichert-Hellert and Mathilde Kersting
}

First published online 12 February 2010

doi:10.1017/S1368980009005503 Published by Cambridge University Press, 16 April 2009

On page 2310 in the subsection Statistical analysis,

Equation 3 should read as follows:

$\operatorname{TEE}(\mathrm{kJ} /$ day $)=388 *$ weight $(\mathrm{kg})-635$

\section{Reference}

Schoen S, Sichert-Hellert W and Kersting M. Validation of energy requirement equations for estimation of breast milk consumption in infants. Public Health Nutrition (2009), 12, 2309-2316. 